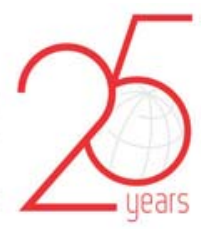

\title{
Intradentinal antimicrobial action and filling quality promoted by ultrasonic agitation of epoxy resin-based sealer in endodontic obturation
}

\section{Abstract}

Murilo Priori ALCALDE ${ }^{1}$

Clóvis Monteiro BRAMANTE1

Rodrigo Ricci VIVAN ${ }^{1}$

Pablo Andrés AMORSO-SILVA ${ }^{1}$

Flaviana Bombarda de ANDRADE ${ }^{1}$

Marco Antonio Hungaro DUARTE
Submitted: March 03, 2017 Modification: May 02, 2017

Accepted: June 02, 2017
The aim of this study was evaluate the influence of ultrasonic activation (UA) of $\mathrm{AH}$ Plus to improve canal and isthmus filling, and analyse the antimicrobial effect against Enterococcus faecalis within dentinal tubules. Material and Methods: Thirty mesial roots of mandibular first molars were selected and divided into 2 groups $(n=15)$ : with and without UA of the sealer. Then the root canals were filled by using the single cone technique, and the specimens were sectioned at 2, 4 and $6 \mathrm{~mm}$ from the apex for stereomicroscope and confocal laser scanner microscopy (CLSM) analysis. In addition, 30 bovine incisors were contaminated with Enterococcus faecalis and divided into 3 groups $(n=10)$. The specimens were obturated by using the single cone technique with (G1) and without (G2) UA of the sealer and G3 as the control group. All were sectioned into $6 \mathrm{~mm}$-long cylinders and stained with LIVE/DEAD to assess bacterial viability by CLSM. Results: The UA of the sealer significantly reduced the presence of unfilled areas in the canal and isthmus area in all sections $(p<0.05)$, and there was a significant increase in sealer penetration in both canals and isthmuses $(p<0.05)$. As regards gaps, a significant reduction was found at 2 and $6 \mathrm{~mm}$ in the isthmus area of the UA group ( $p<0.05)$. Moreover, UA of the sealer significantly reduced bacterial viability in the superficial dentine when compared with the other groups $(p<0.05)$. Conclusion: Ultrasonic activation of the AH Plus sealer promoted a better quality of root canal filling and increased the intratubular penetration of sealer, especially in the isthmus area. Additionally, ultrasonic activation of the sealer increased the intradentinal antimicrobial action against Enterococcus faecalis, mainly in the superficial dentine of the root canal.

Keywords: Endodontics. Bacteria. Ultrasonic. 


\section{Introduction}

Adequate obturation of the root canal system is required after biomechanical procedures, to ensure the long-term success of endodontic treatment ${ }^{20}$. During root canal obturation, an important objective of using endodontic sealers is to fill the spaces that cannot be reached by gutta-percha ${ }^{6}$. However, the anatomical complexities of the root canal system (isthmuses, fins and ramifications) may also interfere with complete obturation ${ }^{2}$.

The presence of isthmuses has a negative effect on the quality of root canal filling ${ }^{13}$ as the obturation materials barely reach and fill these recesses ${ }^{4,5}$. To overcome these drawbacks and improve the filling quality in terms of reducing unfilled areas and gaps, and promoting more effective penetration of sealer into dentinal tubules, recent studies have recommended the ultrasonic activation (UA) of sealers before obturation with gutta-percha7,16. However, this effect has only been studied in single rooted teeth with single canals, and no studies evaluating these aspects in teeth with anatomical complexities have been conducted so far.

Within the dentinal tubules, bacteria such as Enterococcus faecalis ( $E$. faecalis) have capacity to penetrate deeply and offer resistance to the antimicrobial agents used in endodontics ${ }^{29}$. These bacteria are the microorganisms most frequently isolated from persistent endodontic infections ${ }^{19,22}$. Although the $\mathrm{AH}$ Plus sealer has been studied by several authors, and has shown good antimicrobial effect against $E$. faecalis ${ }^{18,28}$, this factor might be dependent on the depth of penetration of the sealer. In addition, sealer penetration into the dentinal tubules should be considered beneficial because of its bacterial entombing action ${ }^{10,15}$. Based on the foregoing considerations, it would be interesting to assess the effect of ultrasonic activation of the sealer to enhance the antimicrobial activity against $E$. faecalis within the dentinal tubules.

Therefore, the aim of the present study was to evaluate the influence of ultrasonic activation of the $\mathrm{AH}$ Plus sealer to improve root canal and isthmus filling in mandibular molars, and analyse the antimicrobial effect against E. faecalis within the dentinal tubules. The null hypotheses tested were as follows:

Ultrasonic activation of the endodontic sealer would not improve the filling quality of the canal and isthmus.
There would be no difference in the adaptation of the sealer/dentine interface and intratubular penetration when ultrasonic activation was performed in the mesial roots of mandibular molars.

The ultrasonic activation would not improve the intradentinal antimicrobial activity of $\mathrm{AH}$ Plus against E. faecalis.

\section{Material and methods}

\section{Root canal and isthmus filling quality \\ Sample Selection}

The ethics committee approved this research (CEP 788274). The sample calculation was performed before the mechanical test by using the G*Power v3.1 for Mac (Heinrich Heine, University of Düsseldorf) by selecting the Wilcoxon- Mann-Whitney test of the t-test family. The alpha-type error of 0.05 , a beta power of 0.95 , and a ratio N2/N1 of 1 were also stipulated. The test showed a total of 8 samples for each group as the ideal size for noting significant differences. However, we used an additional $20 \%$ of instruments to compensate possible atypical values that might induce samples loss. To select mandibular molars with similar anatomical characteristics, 30 extracted mandibular first molars were anatomically paired by means of micro-computed tomography (micro-CT) SkyScan model 1174 (SkyScan, Kontich, Belgium) with an isotropic resolution of $16.82 \mu \mathrm{m}$. The images obtained of each specimen were reconstructed with Nrecon software (v.1.6.3 NRecon; Bruker-microCT, Belgium), providing images of the internal structures of axial sections of the canals in BMP format.

Based on the three dimensional models, anatomical pairing was achieved by selecting teeth of similar lengths and presenting the mesial root with Vertucci's type IV canal configuration ${ }^{26}$ and type $\mathrm{V}$ isthmus classification according to $\mathrm{Hsu}$ and $\mathrm{Kim}^{9}$ (1997), defined as the presence of complete communication between the two mesial canals. According to this classification, 30 mandibular molars were selected and randomly divided into two groups $(n=15)$.

Finally, the total volume of each root canal system was calculated by using the Ctan v.1.12 software (Bruker-microCT), and the Mann-Whitney test was performed to confirm the even distribution of canal volumes between the two groups $(P>0.05)$. 
Sample preparation

The tooth crowns were removed at the cementoenamel junction level by using a $0.3 \mathrm{~mm}$ thick diamond disk fixed in an Isomet saw (Isomet, Buehler, Lake Bluff, Illinois, USA). The apical patency was determined by inserting a size $10 \mathrm{~K}$-file (Dentsply Maillefer, Ballaigues, Switzerland) until it reached the apical foramen. Then working length (WL) was established at $1 \mathrm{~mm}$ short of the apical foramen.

A single operator prepared all the root canals using the Mtwo rotary instrumentation system (VDW, Munich, Germany) until a 35.04 diameter was obtained. Root canals were irrigated with $2.5 \mathrm{~mL}$ of $2.5 \%$ sodium hypochlorite $(\mathrm{NaOCl})$ after each instrument by using a disposable syringe and a $27-G$ NaviTip needle (Ultradent, South Jordan, UT). On conclusion of root canal instrumentation, three applications of $2.5 \mathrm{~mL}$ of $2.5 \% \mathrm{NaOCl}$ and $17 \%$ EDTA were made by means of passive ultrasonic activation (PUI) for $20 \mathrm{~s}$ each, to achieve improved isthmus cleaning ${ }^{24}$. Then, the root canals were finally irrigated with $5 \mathrm{~mL}$ of saline solution and dried with paper points.

\section{Obturation of the specimens}

The AH Plus sealer (Dentsply Maillefer, Ballaigues, Switzerland) was manipulated in accordance with the manufacturer's specifications. Rhodamine-B dye (Sigma-Aldrich, St Louis, USA) at $0.1 \%$ concentration was added to promote sealer fluorescence to enable viewing by confocal laser scanning microscopy (CLSM), as in previous studies ${ }^{7}$. Equal portions of approximately $0.1012 \mathrm{~g}$ of paste $A$ and $B$ were weighed in an analytical precision balance AR2140 (Ohaus Corporation, Shanghai, China) for the obturation of each specimen.

The sealer was inserted into the root canals with a Lentulo spiral \#35 at a low speed of 200 rpm, by using the VDW Silver Reciproc motor (VDW, Munich, Germany) in rotary function. After sealer insertion in Group 1 specimens $(n=15)$, the sealer was ultrasonically agitated (UA) for $20 \mathrm{~s}$ in each mesial canal, $2 \mathrm{~mm}$ short of the WL, in the bucco-lingual direction, by using an Irrisonic tip (Helse, São Paulo, $\mathrm{SP}$, Brazil). For the purpose of UA, an ultrasonic device (Jet Sonic; Gnatus, SP, Brazil) was used at $20 \%$ of the power scale. In Group $2(n=15)$, no ultrasound activation (NUA) was applied after sealer insertion.

Subsequently, a 35.04 gutta-percha cone (VDW, Munich, Germany) was inserted into each canal up to the $W L$, and the material was seared off and compacted with a heated plugger $1 \mathrm{~mm}$ below the canal orifice. The excess sealer was removed and the coronal portion was sealed with a provisional filling material (Coltosol, Coltene, Altstatten, Switzerland). All specimens were then stored at $37^{\circ} \mathrm{C}$ in $100 \%$ humidity for 7 days to allow the sealers to set completely.

Analyses of unfilled area, gaps at the sealer/ dentine interface and sealer penetration

The specimens were horizontally sectioned at 2, 4 and $6 \mathrm{~mm}$ from the apex with a $0.3 \mathrm{~mm}$ Isomet saw (Buehler, Lake Bluff, IL) at 200 rpm, under continuous water cooling to prevent frictional heat, resulting in a total of 90 slices. All the slices were polished with a disc polishing machine under continuous water-cooling (Arotec, Cotia, São Paulo, Brazil) to produce a highly reflective surface.

A high-resolution stereomicroscope (Stemi 2000C; Carl Zeiss, Jena, Germany) was used at $8 \times$ magnification to calculate the percentage of unfilled areas. By means of Axiovision software (Carl Zeiss), the corresponding areas of the canals and isthmuses were divided and analysed separately. The total area of the canals and isthmuses of each cross section and the visible unfilled areas were measured. The percentages of unfilled areas in relation to the total area of the canal and isthmus were then calculated.

After evaluation by stereomicroscopy, all the samples were observed under an inverted Leica TCSSPE confocal laser-scanning microscope using a $10 \times$ objective (Leica Microsystems GmbH, Mannheim, Germany) at $10 \mu \mathrm{m}$ below the dentine surface. The absorption and emission wavelengths for rhodamine-B were set to 540 and $590 \mathrm{~nm}$. All images were recorded using the fluorescent mode to a size of $1024 \times 1024$ pixels. Adaptation at the sealer/dentine interface and sealer penetration into the dentinal tubules of the canals and isthmuses were evaluated based on the methods used in other studies ${ }^{13,14}$ and use of Image J V1.46r software (National Institutes of Health, Bethesda, MD, USA). The canals and isthmuses were analysed separately. The perimeter of the canal walls was obtained; the areas in segments where the sealer penetrated into the dentinal tubules, and where gaps appeared at the sealer/dentine interface were obtained and converted into percentages. The same procedure was performed for the isthmus, measuring the mesial and distal walls only.

A single operator, blinded to the sample 
group, performed all the measurements, and the measurements were repeated twice to ensure reproducibility.

\section{Intradentinal antimicrobial activity}

\section{Sample Preparation}

The crowns of thirty bovine incisor teeth and 2 apical $\mathrm{mm}$ were removed; the samples were standardized to $6 \mathrm{~mm}$ lengths by using an Isomet saw (Isomet 1000, Buehler Ltd, Lake Bluff, IL, USA) with a diamond disk at $250 \mathrm{rpm}$, under irrigation. The root canals were prepared using $K$ files (Dentsply) up to \#80. Teeth with a wider root canal were discarded. The inorganic part of the smear layer was removed with $17 \%$ ethylenediaminetetraacetic acid (EDTA) (Biodinâmica Química e Farmacêutica, Ibiporã, PR, Brazil) for $5 \mathrm{~min}$, and the canals were washed with deionized water. Two layers of red nail polish (L'Oréal Colorama, Rio de Janeiro, RJ, Brazil) were used to cover the external surface of the samples, and dried for $24 \mathrm{~h}$, before being autoclaved at $121^{\circ} \mathrm{C}$.

\section{Contamination protocol}

E. faecalis (ATCC 29212) was reactivated in Brain
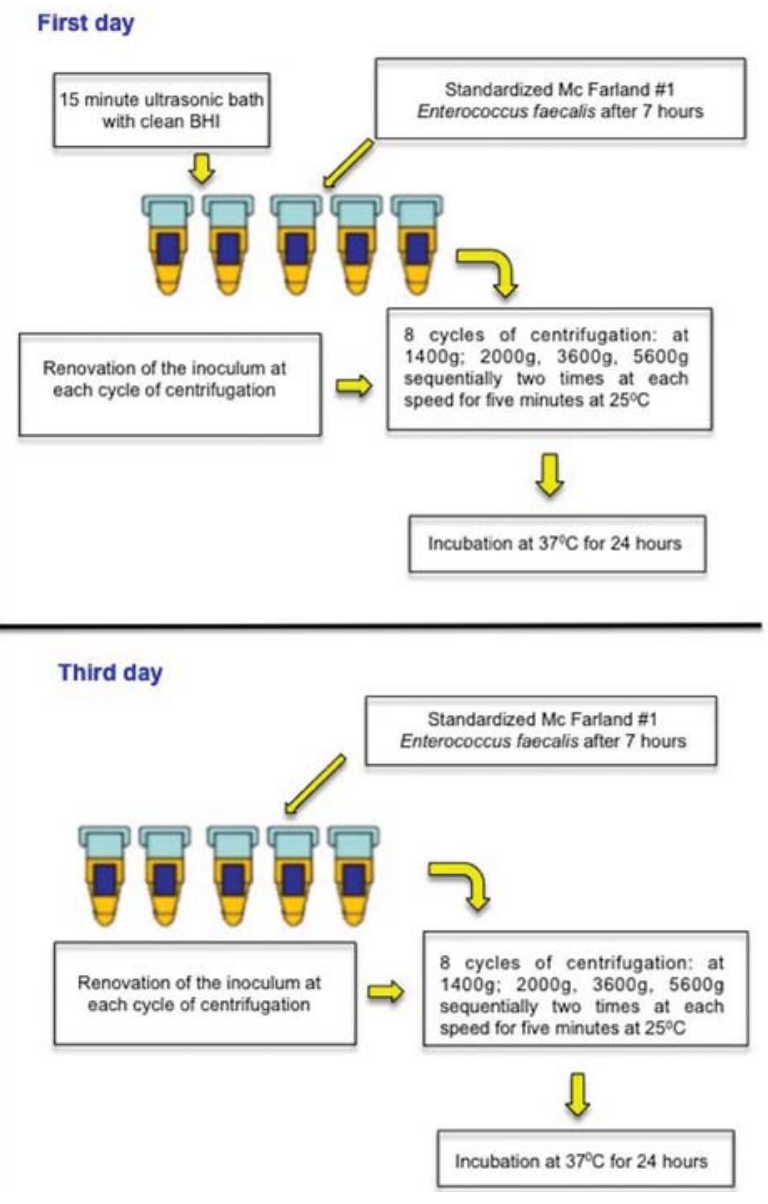

Figure 1- Flowchart of the contamination protocol
Heart Infusion broth (BHI, Difco, Kansas City, MO, USA) and maintained at $37^{\circ} \mathrm{C}$ for $24 \mathrm{~h}$. The bacterial culture was transferred to another BHI flask and incubated for further $24 \mathrm{~h}$ in order to achieve exponential growth. This culture was adjusted to McFarland standard No. $1\left(3 \times 10^{8} \mathrm{CFU} / \mathrm{mL}\right)$ with a spectrophotometer (Bel Photonics do Brasil Ltda, Osasco, SP, Brazil). The contamination model, proposed by Andrade, et al. ${ }^{1}$ (2016), proceeded as follows (flowchart in Figure 1).

\section{Sample Obturation}

After the contamination procedure, the samples were removed from the BHI broth and dried with sterile paper points size 80 (Dentsply Maillefer, Tulsa, USA). The AH Plus sealer was manipulated on a sterile plate in accordance with the manufacturer's instructions. The sealer was placed in each root canal by using a K-File size 70 (Dentsply Maillefer, Tulsa, USA). Then the specimens were divided into 2 groups $(n=10)$ according to ultrasonic activation of the sealer: ultrasonically agitated (G1) and non-ultrasonically agitated (G2) groups. In Group G1 activation was performed with an Irrisonic file (Helse, São Paulo, Brasil) adapted to an ultrasonic device (Jet-Sonic Four
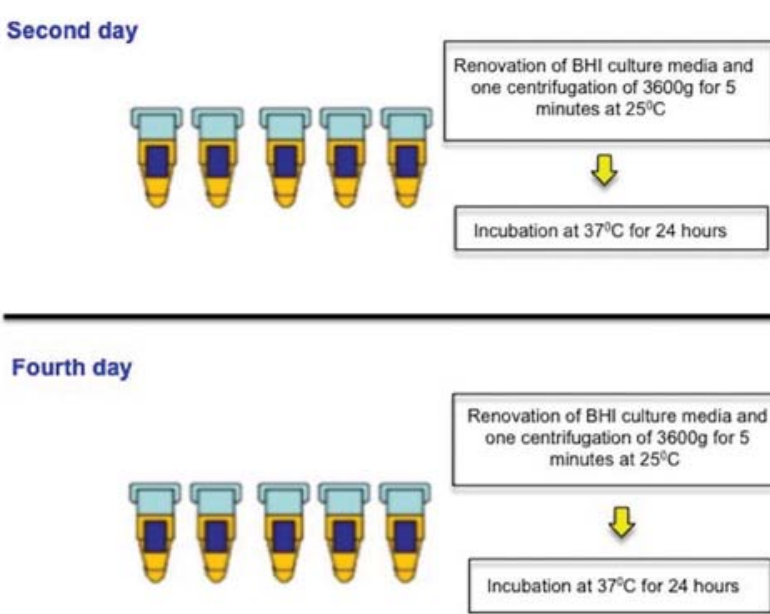

Fifth day
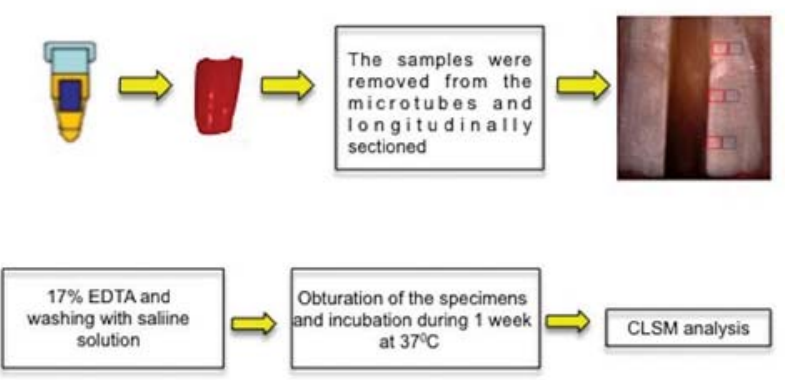
Plus; Gnatus, Ribeirão Preto, SP, Brazil) in "endo" mode (20\% power). Because the ultrasonic oscillation occurs in a single plane, the file was activated for 20 seconds in the buccolingual direction as a standardization procedure. After this, an 80.02 guttapercha cone (Dentsply Maillefer) was inserted into the root canal to complete obturation and the excess was removed with a size 15 surgical blade. Group G2 was obturated in the same manner as G1, however, without previous ultrasonic activation. A third Group (G3) $(n=10)$ did not receive any treatment and served as positive control. Afterwards, the specimens were inserted into sterilized microtubules and incubated at $37^{\circ} \mathrm{C}$ for one week.

\section{Confocal laser scanning microscopy (CLSM) analysis}

After the above-mentioned time interval, the specimens were longitudinally sectioned by using an Isomet saw with a diamond disc, cooled with sterilized saline solution. The smear layer produced by this sectioning was removed with $2.5 \mathrm{~mL}$ of $17 \%$ EDTA for $3 \mathrm{~min}$, and the samples were washed with sterilized saline solution. The halves of the dentinal tubes were stained with $30 \mu \mathrm{L}$ of LIVE/DEAD ${ }^{\circledR}$ BacLightTM Bacterial Viability stain (Molecular Probes, Eugene, OR, USA) for $20 \mathrm{~min}$. This kit contains SYTO $9^{\circledR}$ dye, which stains live bacteria with a green pigment, and propidium iodine dye, which stains dead bacteria with a red pigment, thus enabling viable bacteria to be easily identified. The samples were examined by two blinded calibrated examiners with an inverted Leica TCS-SPE confocal microscope (Leica Microsystems GmbH, Mannheim, Baden-Württemberg, Germany) by using a $40 \mathrm{X}$ magnification oil lens. The images were obtained with $1 \mu \mathrm{m}$ step size, in a $1024 \times 1024$ pixel format. For each specimen, 3 superficial (close to the root canal surface) and 3 deep (close to the external root surface) images were acquired and fragmented using the Leica Application Suite-Advanced Fluorescence software (LAS AF, Leica, Mannheim, Baden-Württemberg, Germany). For an objective analysis, the CLSM images were converted into "tiff" format by the LAS AF software. These images were exported to the bioImageL TM v21 software in order to quantify the percentage of live (green fluorescence) and dead (red fluorescence) bacteria.

\section{Statistical analyses}

Because of the absence of normal distribution, observed by using the Shapiro-Wilk test, the MannWhitney test was used to analyse the influence of ultrasonic activation by means of stereomicroscopy and CLSM analysis. Bacterial viability data were evaluated statistically with the Kruskal-Wallis and Dunn tests. The Prism 6.0 software (GraphPad Software Inc., La Jolla, USA) was used as the analytical tool, and the level of significance was set at $5 \%$.

Table 1- Median, minimum and maximum values in percentage (\%) of unfilled areas of the canal and isthmus

\begin{tabular}{cccccc}
\hline & Canal & & Isthmus \\
\hline $\begin{array}{c}\text { Unfilled areas 2 } \\
\mathbf{m m}(\%)\end{array}$ & $\begin{array}{c}\text { Unfilled areas 4 } \\
\mathbf{m m}(\%)\end{array}$ & $\begin{array}{c}\text { Unfilled areas 6 } \\
\mathbf{m m}(\%)\end{array}$ & $\begin{array}{c}\text { Unfilled areas 2 } \\
\mathbf{m m}(\%)\end{array}$ & $\begin{array}{c}\text { Unfilled areas 4 } \\
\mathbf{m m}(\%)\end{array}$ & $\begin{array}{c}\text { Unfilled areas 6 } \\
\mathbf{m m}(\%)\end{array}$ \\
$0.0(0.0-4.89)^{\mathrm{a}}$ & $0.0(0.0-3.28)^{\mathrm{a}}$ & $0.0(0.0-4.49)^{\mathrm{a}}$ & $0.0(0.0-11.98)^{\mathrm{a}}$ & $0.0(0.0-15.66)^{\mathrm{a}}$ & $0.0(0.0-11.88)^{\mathrm{a}}$ \\
\hline $0.11(0.0-13.15)^{\mathrm{b}}$ & $1.57(0.0-13.65)^{\mathrm{b}}$ & $2.33(0.0-5.80)^{\mathrm{b}}$ & $5.46(0.0-53.27)^{\mathrm{b}}$ & $14.38(0.0-45.35)^{\mathrm{b}}$ & $12.03(0.0-66.02)^{\mathrm{b}}$ \\
\hline
\end{tabular}

A different letter in each column represents statistical differences between the ultrasonically agitated (UA) and nonultrasonically agitated $(\mathrm{NUA})$ groups $(\mathrm{p}<0.05)$

Table 2- Median, minimum and maximum of gaps and sealer penetration segments (SP) in percentages (\%) of the canal and isthmus

\begin{tabular}{|c|c|c|c|c|c|c|c|c|c|c|c|c|}
\hline & $\begin{array}{c}\text { Canal } \\
\text { gap } 2 \\
\text { mm (\%) }\end{array}$ & $\begin{array}{c}\text { Canal } \\
\text { gap } 4 \\
\text { mm (\%) }\end{array}$ & $\begin{array}{c}\text { Canal } \\
\text { gap } 6 \text { mm } \\
(\%)\end{array}$ & $\begin{array}{l}\text { Isthmus } \\
\text { gap } 2 \\
\text { mm (\%) }\end{array}$ & $\begin{array}{l}\text { Isthmus } \\
\text { gap } 4 \\
\text { mm (\%) }\end{array}$ & $\begin{array}{l}\text { Isthmus } \\
\text { gap } 6 \\
\text { mm (\%) }\end{array}$ & $\begin{array}{l}\text { Canal SP } \\
2 \mathrm{~mm}(\%)\end{array}$ & $\begin{array}{l}\text { Canal SP } \\
4 \mathrm{~mm}(\%)\end{array}$ & $\begin{array}{l}\text { Canal } \\
\text { SP } 6 \text { mm } \\
(\%)\end{array}$ & $\begin{array}{l}\text { Isthmus } \\
\text { SP } 2 \text { mm } \\
(\%)\end{array}$ & $\begin{array}{l}\text { Isthmus } \\
\text { SP } 4 \mathrm{~mm} \\
(\%)\end{array}$ & $\begin{array}{c}\text { Isthmus } \\
\text { SP } 6 \\
\text { mm (\%) }\end{array}$ \\
\hline UA & $\begin{array}{l}0.0 \\
(0.0- \\
9.49)^{\mathrm{a}}\end{array}$ & $\begin{array}{c}0.0 \\
(0.0- \\
9.96)^{\mathrm{a}}\end{array}$ & $\begin{array}{c}4.18 \\
(0.0- \\
16.68)^{a}\end{array}$ & $\begin{array}{c}0.0 \\
(0.0- \\
9.31)^{\mathrm{a}}\end{array}$ & $\begin{array}{c}0.0 \\
(0.0- \\
32.63)^{a}\end{array}$ & $\begin{array}{c}0.0 \\
(0.0- \\
40.06)^{a}\end{array}$ & $\begin{array}{c}83.16 \\
(76.91- \\
100.0)^{a}\end{array}$ & $\begin{array}{c}89.03 \\
(67.23- \\
100.0)^{a}\end{array}$ & $\begin{array}{c}90.88 \\
(58.58- \\
100.0)^{a}\end{array}$ & $\begin{array}{c}87.05 \\
(6.0- \\
100.0)^{a}\end{array}$ & $\begin{array}{c}84.36 \\
(24.33- \\
100.0)^{a}\end{array}$ & $\begin{array}{c}76.25 \\
(24.4- \\
100.0)^{a}\end{array}$ \\
\hline NUA & $\begin{array}{c}4.40 \\
(0.0- \\
20.46)^{a}\end{array}$ & $\begin{array}{c}6.43 \\
(0.0- \\
23.03)^{a}\end{array}$ & $\begin{array}{c}10.74 \\
(0.0- \\
28.07)^{b}\end{array}$ & $\begin{array}{c}0.0 \\
(0.0- \\
52.55)^{\mathrm{b}}\end{array}$ & $\begin{array}{c}0.0 \\
(0.0- \\
30.69)^{a}\end{array}$ & $\begin{array}{c}2.50 \\
(0.0- \\
34.43)^{b}\end{array}$ & $\begin{array}{c}62.73 \\
(35.14- \\
100.0)^{b}\end{array}$ & $\begin{array}{c}74.77 \\
(38.80- \\
100.0)^{\mathrm{b}}\end{array}$ & $\begin{array}{c}71.47 \\
(19.12- \\
100.0)^{b}\end{array}$ & $\begin{array}{c}0.0 \\
(0.0- \\
82.11)^{\mathrm{b}}\end{array}$ & $\begin{array}{c}4.89 \\
(0.0- \\
100.0)^{\mathrm{b}}\end{array}$ & $\begin{array}{c}36.79 \\
(0.0- \\
76.22)^{\mathrm{b}}\end{array}$ \\
\hline
\end{tabular}

A different letter in each column represents statistical differences between the ultrasonically agitated (UA) and nonultrasonically agitated (NUA) groups $(p<0.05)$ 


\section{Results}

\section{Root canal/isthmus filling quality}

The median and the range of percentages of unfilled areas obtained from the stereomicroscopy analysis are shown in Table 1. In all sections, ultrasonic activation of the sealer significantly reduced the presence of unfilled areas in the canal and isthmus areas $(p<0.05)$
(Figure 2A, B).

Results of the CLSM examination are presented as median and ranges in Table 2. Overall, ultrasonic activation of the sealer showed a significant improvement in sealer penetration into the dentinal tubules in both canals and isthmuses $(p<0.05)$ (Figure 2C, D). Gaps at the sealer/dentine interface were significantly reduced at 2 and $6 \mathrm{~mm}$ in the isthmus
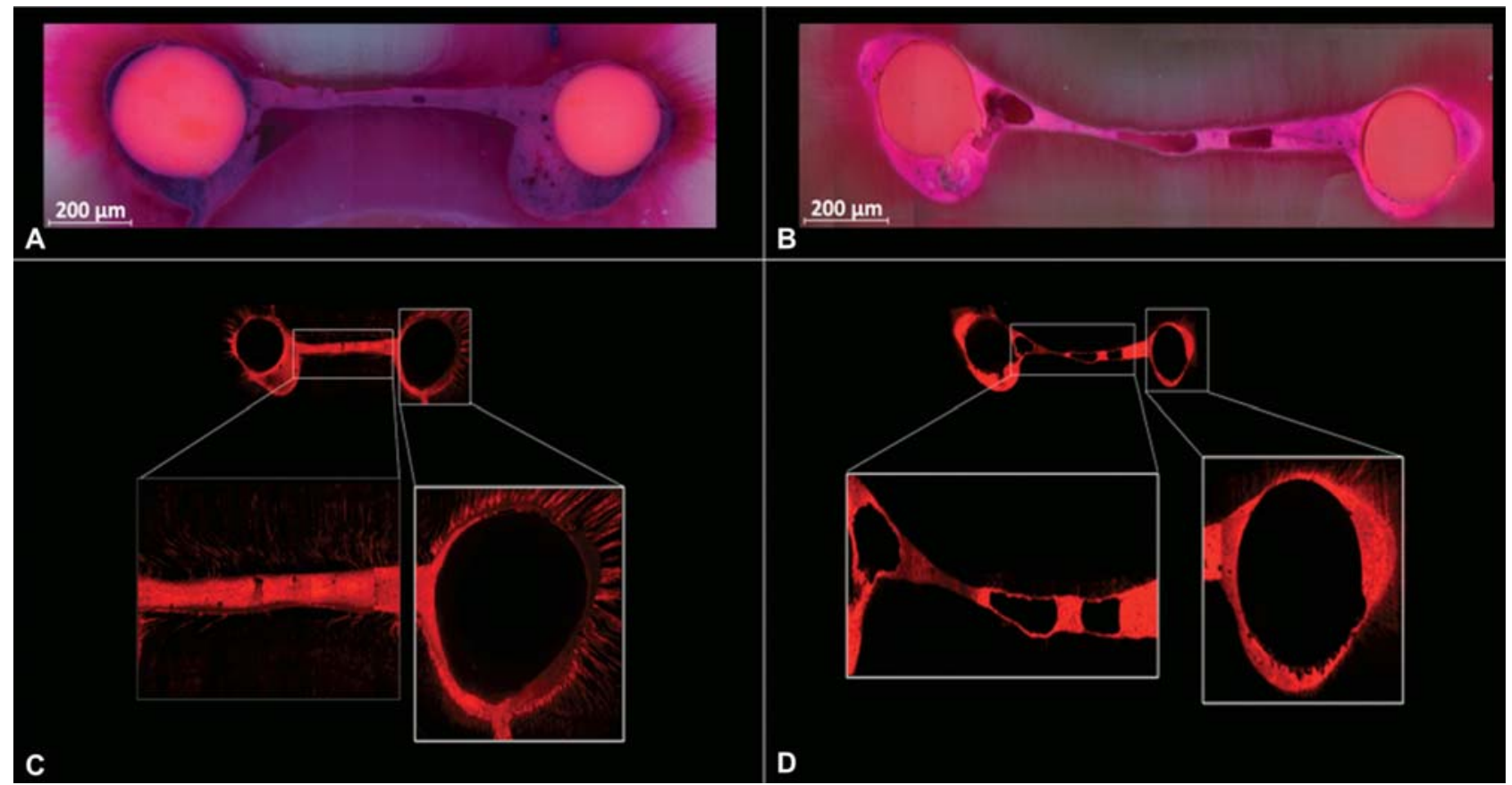

Figure 2- Representative stereomicroscopic ( $A$ and $B$ ) and confocal images ( $C$ and $D$ ) of filled mesial roots of mandibular molars at $4 \mathrm{~mm}$ from the apex. (A) Satisfactory filling without gaps in the canal and isthmus in the UA group. (B) Gaps inside the canal and isthmus in the NUA group. (C) A significant sealer penetration into the dentinal tubules of the canal and isthmus is observed in the UA group, contrary to the NUA group (D) where fewer dentinal tubules are filled with sealer

\section{Superficial Dentine}

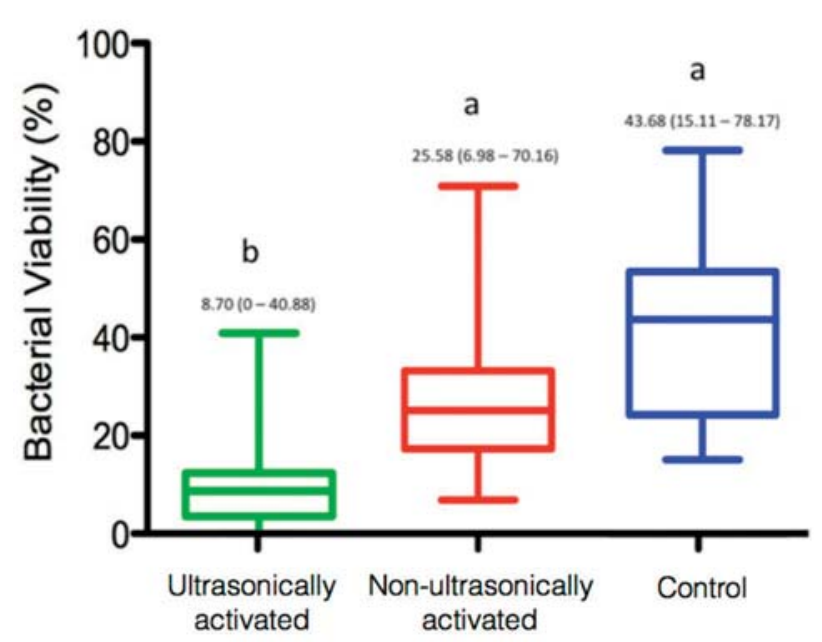

Groups

\section{Deep Dentine}

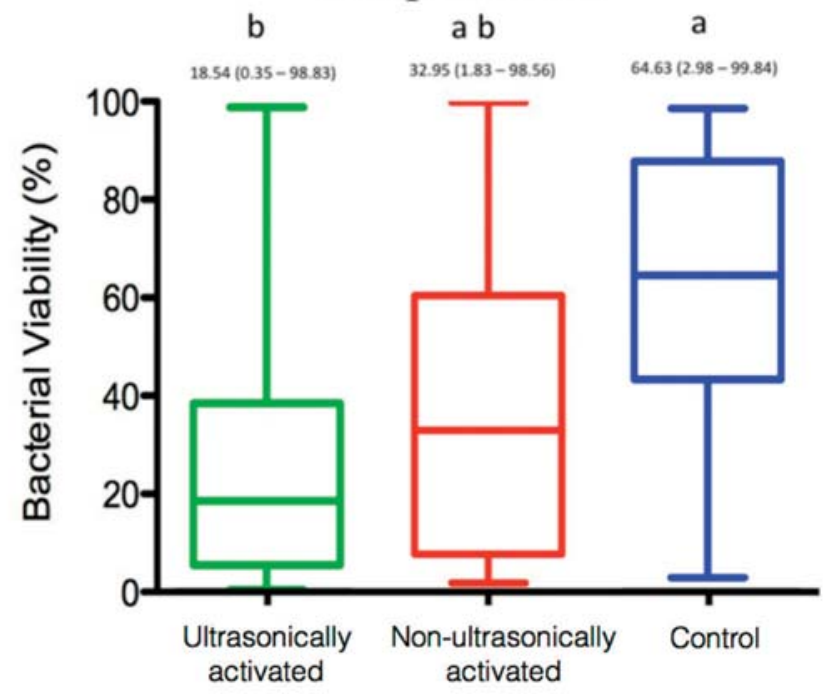

Groups

Figure 3- Graph representing the median, minimum and maximum range of the percentage of bacterial viability on the superficial dentine (A) and deep dentine (B): ultrasonically activated (G1), non-ultrasonically activated (G2) and control group (G3). Different letters represent statistical differences between the groups 


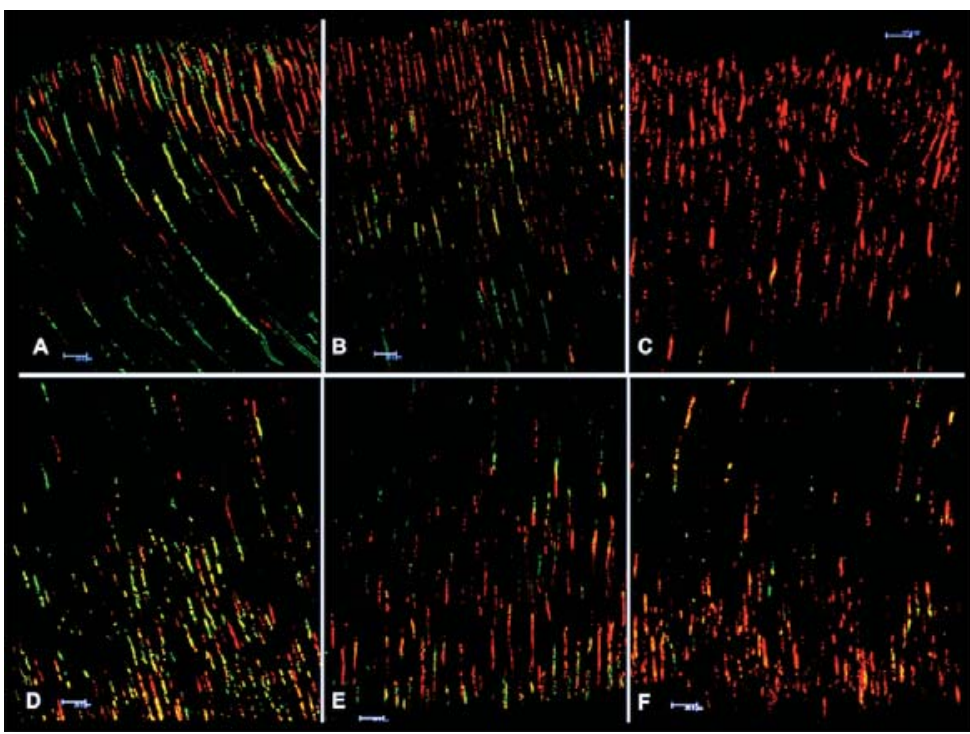

Figure 4- Representative images of bacterial viability in superficial ( $A, B$ and $C$ ) and deep ( $D, E$ and $F)$ dentine obtained by confocal laser scanning: A, D (control group), B, E (without ultrasonic activation of the sealer) and C, F (with ultrasonic activation). Red colour denotes dead bacteria and green denotes live bacteria

area and at $6 \mathrm{~mm}$ only in the canals when the sealer was ultrasonically agitated $(p<0.05)$. At $4 \mathrm{~mm}$, there was no statistically significant difference between the groups ( $p>0.05)$.

\section{Intradentinal antimicrobial activity}

The percentages of bacterial viability in superficial and deep dentine are shown in Figure 3. In superficial dentine, ultrasonic activation significantly reduced the bacterial viability when compared with the other groups $(p<0.05)$. As regards deep dentine, there was a significant reduction in bacterial viability only when the ultrasonically agitated group (G1) was compared with Control group (G3) $(p<0.05)$.

\section{Discussion}

Ultrasonic activation of the endodontic sealer significantly improved the filling quality (canal and isthmus), adaptation of sealer/dentine interface and intratubular penetration in the UA group. The antimicrobial activity was also enhanced by UA in superficial dentine. Therefore, our entire null hypothesis was rejected. The favourable results obtained have a significant importance, if we consider previous studies $3,25,27$ that showed deficiency in properly filling and disinfecting these complex areas was capable of leaving tissue remnants, bacteria and debris, increasing the risk of post-treatment apical periodontitis.
In the present study, PUI for 1 min per canal was performed in both groups to achieve an improved isthmus cleaning ${ }^{8}$ and the sealer was observed to have the ability to flow into cleaned isthmuses in both groups. However, a low quantity of sealer was observed inside the isthmus in the NUA group, leading to greater presence of unfilled areas in all the cross sections, irrespective of the isthmus width or length (Figure 2B).

Furthermore, to analyse the influence of ultrasonic activation of the sealer and quantify only the sealer component inside the isthmus, the single cone technique was used in root canal fillings. This was done to enable proper differentiation between gutta-percha and sealer, because when thermoplasticised techniques are used, a single obturation mass is produced, making it difficult to differentiate between the two materials separately. Indeed, Marciano, et al. ${ }^{13}$ (2011) reported that the presence of isthmuses increased the incidence of unfilled areas, even when using thermoplasticised techniques. Moreover, the single cone technique allowed the insertion of a standard amount of gutta-percha with reduced compaction forces when compared with other techniques that could push the sealer and gutta-percha into the isthmus, thereby interfering with the main study objective. The abovementioned factors, previous anatomical pairing, and the similar sealer volume inserted into each specimen may have provided more reliable results. Therefore, the results found in the UA group possibly occurred exclusively as a result of the ultrasonic activation of the sealer. 
The improvement in the amount of sealer that entered inside the isthmus in the UA group was probably caused by the transmission of acoustic microstreaming energy produced by the ultrasonic tip, which could have forced the sealer into these areas. This effect regularly occurs in the irrigating solution while performing passive ultrasonic irrigation ${ }^{8,24}$.

Although the results of the confocal microscopic analysis of both the groups showed gaps at the sealer/ dentine interface, ultrasonic activation of the sealer improved this aspect by significantly reducing the gaps to minimum values in some canal cross sections. Furthermore, higher percentages of intratubular sealer penetration were observed in the canal and isthmus region of the UA group at all the levels evaluated. Previous studies presented similar results using single rooted teeth ${ }^{7,16}$. Macedo, et al. ${ }^{12}$ (2014) showed that the ultrasonic activation increased the temperature of irrigants. The same phenomenon can occur during ultrasonic activation of the sealer, which could promote higher flowability and reduce the film thickness, favouring its penetration into dentinal tubules. The medians of sealer penetration of the UA group in all sections were above $76 \%$ when compared with the NUA group, in which penetration values were below $39 \%$. This result is noteworthy if we consider the antibacterial properties of root canal sealers within the dentinal tubules ${ }^{29}$.

This study presented a method for intratubular contamination of bovine dentine proposed by Andrade, et al. ${ }^{1}$ (2016). Bovine teeth are commonly used as an experimental substitute for human teeth because they are easily available ${ }^{21}$. Compared with human dentine, bovine dentine has a higher concentration of dentine tubules per square millimeter, however, this difference is small. On average, the diameter of dentine tubules of bovine teeth is larger than that of human teeth, but this difference is not statistically significant. The percentage of intertubular dentine in bovine teeth is the same as it is in human teeth ${ }^{21}$.

Vera, et al. ${ }^{25}$ (2012) showed that microorganisms remain inside the dentinal tubules and survive after biomechanical preparation and intracanal dressing. Thus, the sealer penetration into the dentinal tubules plays an important role during root canal filling because of the antimicrobial action of these materials and their action of entombing residual microorganism ${ }^{10,15}$. Our results showed that ultrasonic activation of the sealer promoted a significant reduction in $\mathrm{E}$. faecalis viability in superficial dentine when compared with the other groups (Figure 4A, B and C). As regards deep dentine, there was statistically significant reduction in E. faecalis viability only in the ultrasonically agitated group in comparison with the Control group (Figure 4C, $D$ and $F$ ). The AH Plus sealer has antimicrobial action against Enterococcus faecalis ${ }^{18,28}$. The antimicrobial properties of epoxy resin-based sealers may be related to the bisphenol-A diglycidy ${ }^{23}$ or small quantities of formaldehyde ${ }^{11}$ released into the dentinal tubules during the polymerisation process.

The possible explanation of the improvement of the antimicrobial action of the $\mathrm{AH}$ Plus when activated by ultrasonic tip is due to the transmission of acoustic microstreaming energy produced, which increases the sealer penetration into the dentine tubules ${ }^{7,16}$. Thus, the greater sealer penetration may act as a physical barrier and may entomb residual microorganisms, thereby separating them from nutrient sources ${ }^{17}$. In addition, the greater contact between the sealer and microorganisms could favour the antimicrobial action of the $\mathrm{AH}$ Plus, consequently reducing the microorganism viability.

\section{Conclusion}

The ultrasonic activation of the $\mathrm{AH}$ Plus sealer promoted a better quality of root canal filling and increased the intratubular penetration of sealer, especially in the isthmus area. Additionally, ultrasonic activation of the sealer increased the intradentinal antimicrobial action against Enterococcus faecalis, mainly in the superficial dentine of the root canal.

\section{References}

1- Andrade FB, Arias MP, Maliza AG, Duarte MA, Graeff MS, AmorosoSilva $P A$, et al. A new improved protocol for in vitro intratubular dentinal bacterial contamination for antimicrobial endodontic tests: standardization and validation by confocal laser scanning microscopy. J Appl Oral Sci. 2015;23(6):591-8.

2- Ardila CN, Wu MK, Wesselink PR. Percentage of filled canal area in mandibular molars after conventional root-canal instrumentation and after a noninstrumentation technique (NIT). Int Endod J. 2003;36(9):591-8.

3- Carr GB, Schwartz RS, Schaudinn C, Gorur A, Costerton JW. Ultrastructural examination of failed molar retreatment with secondary apical periodontitis: an examination of endodontic biofilms in an endodontic retreatment failure. J Endod. 2009;35(9):1303-9. 
4- De-Deus G, Reis C, Beznos D, Abranches AM, Coutinho-filho T, Paciomik S. Limited ability of three commonly used thermoplasticized gutta-percha techniques in filling oval-shaped canals. J Endod. 2008;34(11):1401-5.

5- Endal U, Shen Y, Knut A, Gao Y, Haapasalo M. A high-resolution computed tomographic study of changes in root canal isthmus area by instrumentation and root filling. J Endod. 2011;37(2):223-7.

6- Gatewood RS. Endodontic materials. Dent Clin North Am. 2007;51(3):695-712

7- Guimaraes BM, Amoroso-Silva PA, Alcalde MP, Marciano MA, Andrade $F B$, Duarte MA. Influence of ultrasonic activation of 4 root canal sealers on the filling quality. J Endod. 2014;40(7):964-8.

8- Gutarts R, Nusstein J, Reader A, Beck M. In vivo debridement efficacy of ultrasonic irrigation following hand-rotary instrumentation in human mandibular molars. J Endod. 2005;31(3):166-70.

9- Hsu YY, Kim S. The resected root surface. The issue of canal isthmuses. Dent Clin North Am. 1997;41(3):529-40.

10- Kokkas AB, Boutsioukis A, Vassiliadis LP, Stavrianos CK. The influence of the smear layer on dentinal tubule penetration depth by three different root canal sealers: an in vitro study. J Endod. 2004;30(2):100-2.

11- Leonardo MR, Silva LA, Tanomaru M Filho, Silva RS. Release of formaldehyde by 4 endodontic sealers. Oral Surg Oral Med Oral Pathol Oral Radiol Endod. 1999;88(2):221-5.

12- Macedo RG, Verhaagen B, Wesselink PR, Versluis M, van der Sluis LW. Influence of refreshment/activation cycles and temperature rise on the reaction rate of sodium hypochlorite with bovine dentine during ultrasonic activated irrigation. Int Endod J. 2014;47(2):147-54.

13- Marciano MA, Ordinola-Zapata R, Cunha TV, Duarte MA, Cavenago $B C$, Garcia RB, et al. Analysis of four gutta-percha techniques used to fill mesial root canals of mandibular molars. Int Endod J. 2011;44(4):321-9.

14- Marciano MA, Guimaraes BM, Ordinola-Zapata R, Bramante CM, Cavenago BC, Garcia RB, et al. Physical properties and interfacial adaptation of three epoxy resin-based sealers. J Endod. 2011;37(10):1417-21.

15- Moon YM, Shon WJ, Baek SH, Bae KS, Kum Ky, Lee W. Effect of final irrigation regimen on sealer penetration in curved root canals. J Endod. 2010;36(4):732-6.

16- Nikhil V, Bansal P, Sawani S. Effect of technique of sealer agitation on percentage and depth of MTA Fillapex sealer penetration: a comparative in-vitro study. J Conserv Dent. 2015;18(2):119-23.
17- Ordinola-Zapata R, Bramante CM, Graeff MS, del Carpio Perochena A, Vivan RR, Camargo EJ, et al. Depth and percentage of penetration of endodontic sealers into dentinal tubules after root canal obturation using a lateral compaction technique: a confocal laser scanning microscopy study. Oral Surg Oral Med Oral Pathol Oral Radiol Endod. $2009 ; 108(3): 450-7$.

18- Prestegaard H, Portenier I, Orstavik D, Kayaoglu G, Haapasalo M, Endal U. Antibacterial activity of various root canal sealers and rootend filling materials in dentin blocks infected ex vivo with Enterococcus faecalis. Acta Odontol Scand. 2014;72(8):970-6.

19- Rôças IN, Siqueira JF Jr, Santos KR. Association of Enterococcus faecalis with different forms of periradicular diseases. J Endod. 2004;30(5):315-20.

20- Schilder H. Filling root canals in three dimensions. Dent Clin North Am. 1967 Nov;723-44.

21- Schilke R, Lisson JA, Bauss O, Geurtsen W. Comparison of the number and diameter of dentinal tubules in human and bovine dentine by scanning electron microscopic investigation. Arch Oral Biol. 2000;45(5):355-61.

22- Siqueira JF Jr, Rôças IN. Polymerase chain reaction-based analysis of microorganisms associated with failed endodontic treatment. Oral Surg Oral Med Oral Pathol Oral Radiol Endod. 2004;97(1):85-94.

23- Slutzky-Goldberg I, Slutzky H, Solomonov M, Moshonov J, Weiss EI, Matalon S. Antibacterial properties of four endodontic sealers. J Endod. 2008;34(6):735-8.

24- van der Sluis LW, Versluis M, Wu MK, Wesselink PR. Passive ultrasonic irrigation of the root canal: a review of the literature. Int Endod J. 2007;40(6):415-26.

25- Vera J, Siqueira Jr JF, Ricucci D, Loghin S, Fernández N, Flores B, et al. One-versus two-visit endodontic treatment of teeth with apical periodontitis: a histobacteriologic study. J Endod. 2012;38(8):1040-52. 26- Vertucci FJ. Root canal anatomy of the human permanent teeth. Oral Surg Oral Med Oral Pathol. 1984;58(5):589-99.

27- von Arx T. Frequency and type of canal isthmuses in first molars detected by endoscopic inspection during periradicular surgery. Int Endod J. 2005;38(3):160-8.

28- Wang Z, Shen Y, Haapasalo M. Dentin extends the antibacterial effect of endodontic sealers against Enterococcus faecalis biofilms. J Endod. 2014;40(4):505-8.

29- Zhang C, Du J, Peng Z. Correlation between Enterococcus faecalis and persistent intraradicular infection compared with primary intraradicular infection: a systematic review. J Endod. 2015;41(8):20713. 